\title{
Water Clusters in Liquid Fuels. Their Role and Surroundings
}

\author{
Kristina Zubow ${ }^{2}$, Anatolij Zubow ${ }^{1}$, Viktor Anatolievich Zubow ${ }^{2, *}$ \\ ${ }^{1}$ Dept. of Computer Science, Humboldt University Berlin, Johann von Neumann Haus, D-12489, Berlin \\ ${ }^{2}$ A IST Handels- und Consulting GmbH, dept. R\&D, D-17192 Groß Gievitz, Germany
}

\begin{abstract}
The long-range order in $n$-hexane, gasoline, diesel and in their mixtures with/without water is investigated by the gravitational mass spectroscopy (GMS). Molecular clusters are analyzed to be present in fuels and mixtures. Using GMS subtraction spectra for water in hydrocarbons, it becomes clear what role water plays and how it interact with the surroundings. Water in fuels is concluded to appear as individual clusters, whose structure (density) depends on the nature of hydrocarbon clusters. The combustion mechanism of hydrocarbons saturated with water will be discussed. Water clusters are suggested to accelerate the diffusion processes of the combustion. Molecular clusters in liquid fuels are formed in stationary gravitational waves of white noises, penetrating the Earth.
\end{abstract}

Keywords Gasoline, diesel, clusters, burning, water, diffusion, white noises

\section{Introduction}

The mixing of different liquids should not lead to the formation of homogeneous systems, the so-called ideal solutions because of cohesive and structural factors, the crucial role of which, unfortunately, is ignored by many researchers. If even simple liquids are considered to be inhomogeneous (long-range order at cluster level), then the mixtures of different miscible liquids even more. On the other hand, we can expect that the heating will lead to the dispersion of the mixture of liquids and the cohesive and structural factors coupled with the positive influence of white noise to the formation of a new long-range order. The mixtures are to be understood as nano colloidal systems where the nanoparticles of different liquids are not miscible with each other although a phase boundary can not be seen with the classical energy-rich methods. However, some simple water clusters (up to hexamers, $3329 \mathrm{~cm}^{-1}$ ) in neon were already recorded with IR spectroscopy by Hibarayashi and Yamada[1]. Nevertheless, a new non-destructive method for analyzing the long-range order in mixtures of liquids is necessary.

Understanding of liquids' states in mixtures will open new fields in nanotechnology, optimize known processes in chemistry (drying, combustion, polymerization), model biological systems, and develop the remote communication of liquids.

In this work, we decided to study the long-range order in fuels, as the most promising topics.

* Corresponding author:

aist@zubow.de (Viktor Anatolievich Zubow)

Published online at http://journal.sapub.org/pc

Copyright (C) 2012 Scientific \& Academic Publishing. All Rights Reserved
To get an idea on the long-range order in liquid fuels is of great economic importance in terms of optimizing combustion processes, dissolution, film formation, and even oil exploration. Scientific interest is dictated by the need to understand the formation mechanisms of clusters, their physical chemical properties as kinetically independent units, the cluster distribution in a liquid furthermore, to investigate cluster surfaces and their gravitational fields. The coming energy problems force to search for new ways to use oil rationally, especially when it will be burned. Combustion engines have reached their limit and new engineering ideas can not significantly reduce the fuel consumption. However, in recent years a number of patents has been applied concerning the possibility of reducing fuel consumption by adding water to it and dispersing the emulsion prior to injection into the cylinder combustion chamber[1-4]. Literature published on this topic is almost simultaneously researched. For instance, to $\mathrm{Fu}$ et al[1] gasolines investigated with gas chromatography are characterized by a cluster structure (up to 20 different clusters); different types of gasoline are even identified with the cluster structure. After passing through a porous ceramic membrane or treatment with electrical current the water-gasoline mixture forms "ultra disperse" clusters.

Modeling the water cluster formation in n-hexane at $300 \mathrm{~K}$ Mudzhikova et al[1] found that three cluster types consisting of 27, 64 and 125 molecules are possible.

The cluster formation energy is found to be really low[1-3] where the cluster stability is ensured by the entropy factor.

Applying traditional methods of physical chemistry it is difficult to detect and identify clusters[1,9,1], however, computer simulations make it possible to calculate hypo-thetical structures with a minimum of energy. 
For a better understanding of the material in this work Figure 1 shows some modeled clusters of elementary liquids (see[1] too) and Figure 2 gives review GMS spectra of some liquid hydrocarbons.

\section{Experimental Part}

As investigation objects $n$-hexane $\left(\mathrm{n}_{20}^{\mathrm{D}}=1.3752\right)$, diesel (DIN EN 228), gasoline (ROZ DIN EN 98) and mixtures of liquids are used. The fuel mixtures are prepared at $293 \mathrm{~K}$ by simple mixing, the hydrocarbons' saturation with distilled water by shaking and following decantation of the upper fraction. Samples are placed in a box being maximally protected from outer energy flows[13]. Measurement method is described in $[8,12,13]$. Before the measurement, the samples are stored for a week under exclusion of light and mechanical fields. The GMS sensor is directly placed inside the sample $(10 \mathrm{ml})$. The negative signal in the GMS $(-f)$ represents the energy release of a collapsed cluster leading to its higher density and crystallization. On the other side the positive signal $(f)$ means the energy absorption at the interaction of the shock wave with the expanded cluster and its melting. The values of collapsed clusters are therefore described with minus and that of expanded one with plus. More information, see in[12]. $\mathrm{M}_{\mathrm{GMS}}$ - average molecular mass of all clusters in Dalton (Da), $\left.\mathrm{M}_{\mathrm{GMS}}=\Sigma|f| \cdot m\right), m-$ cluster mass (Da), $f-$ energetical part of a cluster in ensemble of clusters, $-f$ part of collapsed clusters, $\mathrm{D}_{\mathrm{c}}-$ sum of all collapsed clusters and $\mathrm{N}-$ number of cluster kinds in ensemble, $p$ - shock wave pressure.

According to this Figure the GMS-spectra of hydrocarbons and their mixtures are similarly however, there are some significant differences. For example, the cluster of 20 molecules oscillates in $n$-hexane[8] (labeled with an arrow) as a collapsed cluster while it is shown as expanded one in gasoline.

When 1 vol. \% diesel is added to gasoline, then the GMSspectrum changes dramatically. The strong change in the spectrum continues with further addition of diesel. At a diesel content of 10 to $30 \mathrm{vol}$. \% the distribution of clusters and their interaction with surroundings approach to that one in pure $n$-hexane.

In the literature there is not enough information about clusters formed by organic compounds[8,9,14]. Generally, the simplest molecule clusters, such as benzene dimers[15], complexes of water with acetone[15,16] and other organic compounds with polar groups[17] were studied.
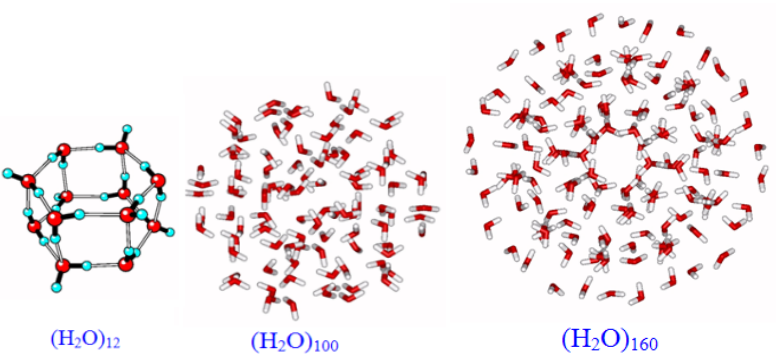

$\left(\mathrm{H}_{2} \mathrm{O}\right)_{160}$

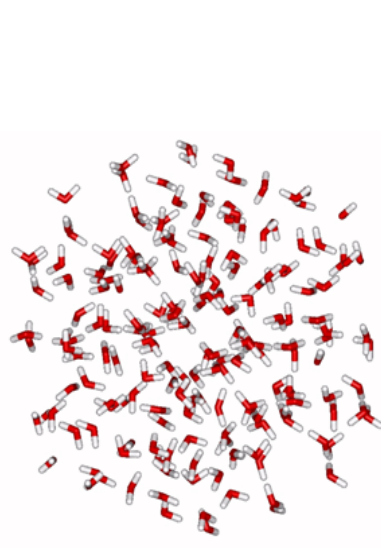

$\left(\mathrm{H}_{2} \mathrm{O}\right)_{184}$

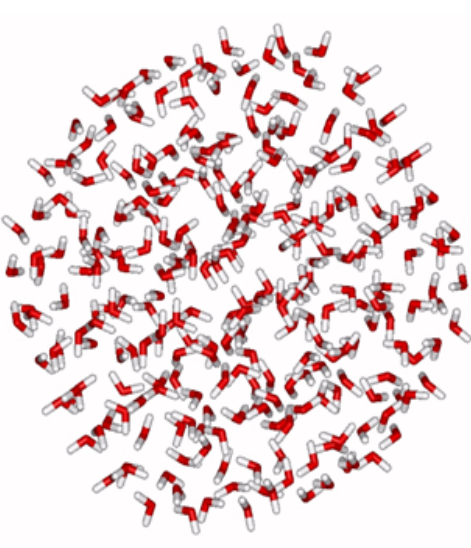

$\left(\mathrm{H}_{2} \mathrm{O}\right)_{280}$

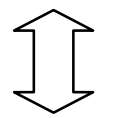

Expanded structure (ES) Collapsed structure (CS)<smiles>COCOCOC</smiles><smiles>COC1O[C@H](OC)[C@H](OC)[C@@H](OC)[C@@H]1OC</smiles>

$\left(\mathrm{CH}_{3} \mathrm{OH}\right)_{6}$

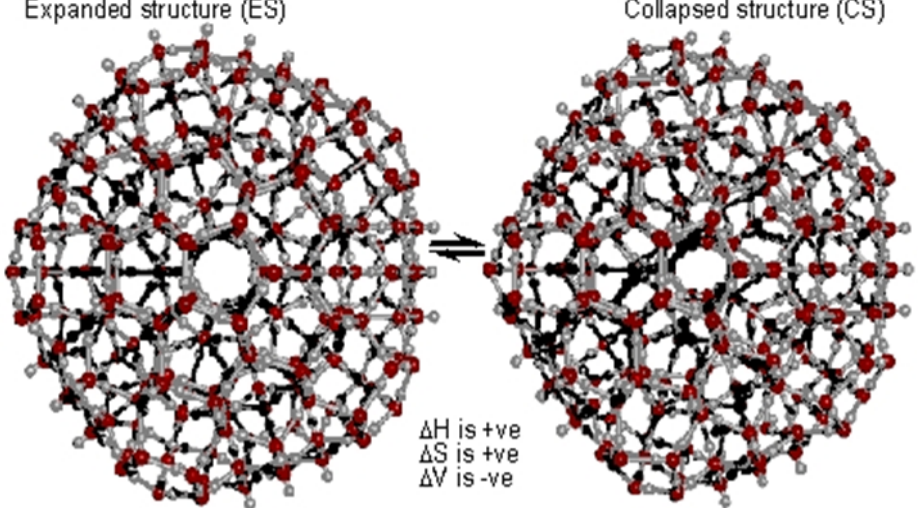

Figure 1. Calculated water cluster models (with kind permission of the professors Chaplin, http://www.lsbu.ac.uk/water/index.html) and A. Lenz, (Sweden) and clusters in methanol experimentally observed by the authors[8] 


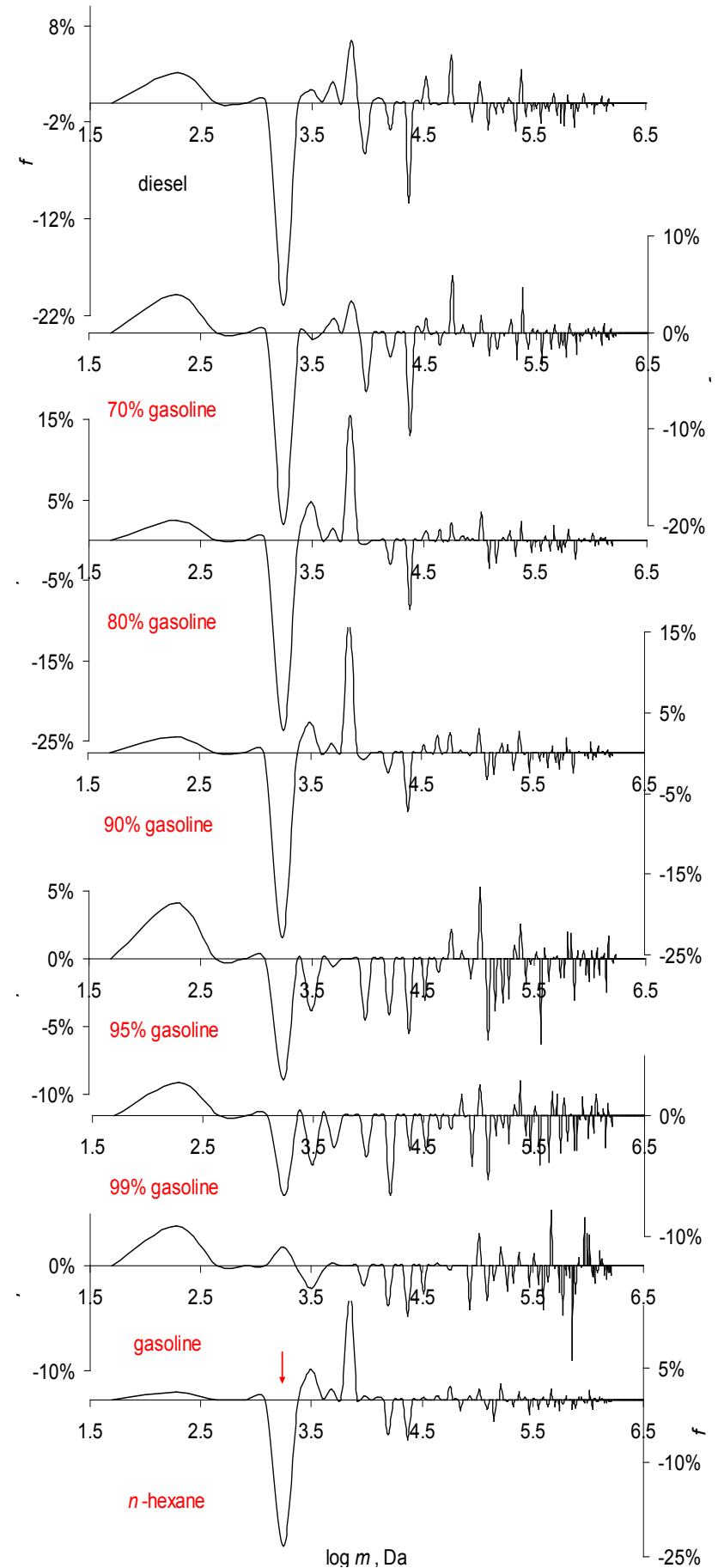

Figure 2. Review GMS spectra of hydrocarbons. $286 \mathrm{~K}$. Cluster ensembles up to 3 million Daltons, $p>1 \mathrm{~N} / \mathrm{m}^{2}$. Diesel and its mixtures with gasoline, vol. \%

As shown in Figure 2 mixtures of organic compounds are characterized by their own long-range order (LRO) at the level of cluster formation, i.e. they are also nano emulsions. Here is of interest the entire range of clusters, therefore. If water is added to gasoline or $n$-hexane (Figure 3 ), then there is a harmonization of the cluster ensembles in the small and medium-sized clusters' range (up to $\log m<3.7$ ). In this mass range, only the long-range order in diesel changed, but marginally. Thus water affects the long-range order of light fuels (gasoline) where LRO of the mixture approaches to that one of medium fuels (diesel). Analyzing the signal intensities of water clusters in $n$-hexane gives an idea where they are in the paraffin. Thus, in the mixture with water, the signal intensity is increased sharply at $\log m=2.3$ compared with pure $n$-hexane (Figure 3, signal is indicated by arrow). This signal in pure water is defined as a signal of the base water cluster consisting of $11 \pm 1$ molecules[8,18]. Its computer model it is shown in Figure 1. The fact that this cluster appears in the expanded form in the hydrocarbon could be an evidence for the destructive influence of $n$-hexane on it while the signal intensity increase indicates on the individualization of the cluster as an oscillator leading to its weakened interaction with the surroundings. In gasoline and diesel, this effect is not pronounced. The signal intensity at $\log \mathrm{m}=2.3$ is very low and almost unchanged. Consequently, this cluster has lost its identity as a result of the interaction with the surroundings and as a mass concentration it is almost nonexistent. The presence of, for example, aromatic structures, traces of alcohols, ketones, and other polar compounds in diesel fuel and gasoline contributes to the disappearance of the water cluster. The surface molecules of this cluster actively interact with the surroundings[17-23] and thus it is exposed to the decomposition, or an equilibrium between the collapsed and expanded forms will be reached, but this is rather unlikely.

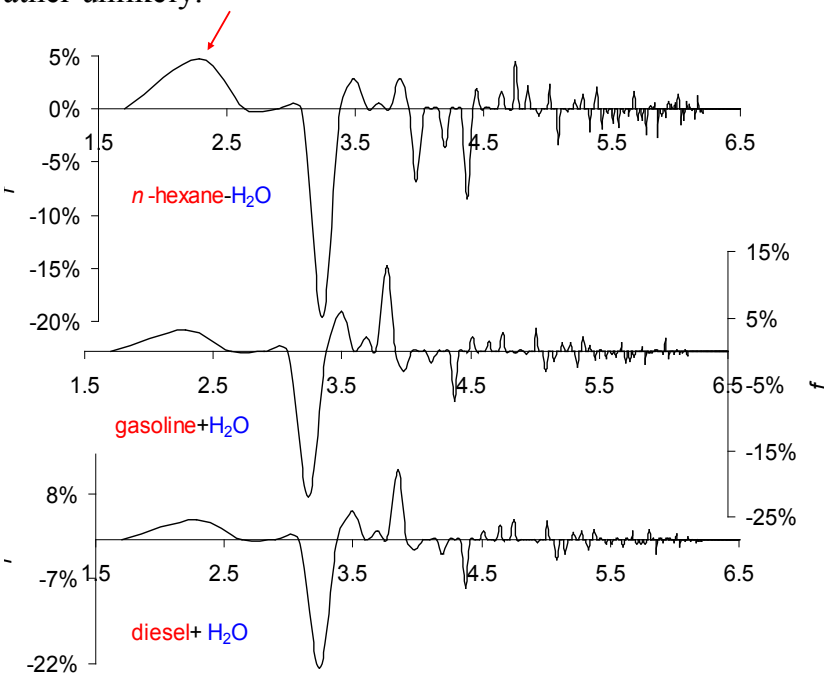

$\log m, \mathrm{Da}$

Figure 3. Review GMS spectra of fuels saturated with water. $286 \mathrm{~K}$. Mass ensembles up to 3 million Daltons, $p>1 \mathrm{~N} / \mathrm{m}^{2}$

The long-range order of water in hydrocarbons can be better understood applying GMS subtraction spectra. Here the signal intensities of hydrocarbons shall be subtracted from those of hydrocarbons saturated with water $(\Delta f)$. This method is not uncontroversial, but it should be applicable to a series of similar substances. The GMS-subtraction spectra of water in hydrocarbons are shown in Figure 4. The Figure shows a different water cluster structures in hydrocarbons and bulk water. Note that the energy characteristics of individual clusters in different surroundings can not be adequately compared. The GMS spectrum of bulk water is to consider as a comparison spectrum for this specific case of 
mixture preparation. In diesel and gasoline, the base water cluster[24] consisting of $11 \pm 1$ molecules is not pronounced, its signal intensity is close to zero, thus indicating a strong interaction with the surroundings.

The water cluster of 100 molecules is in gasoline highly individualized and presented in the collapsed form, while in diesel it is "smeared" as a result of the strong interaction with the surroundings however, it still remains in the collapsed form, mainly. Otherwise, this cluster behaves in hexane, where it occurs as an expanded cluster.

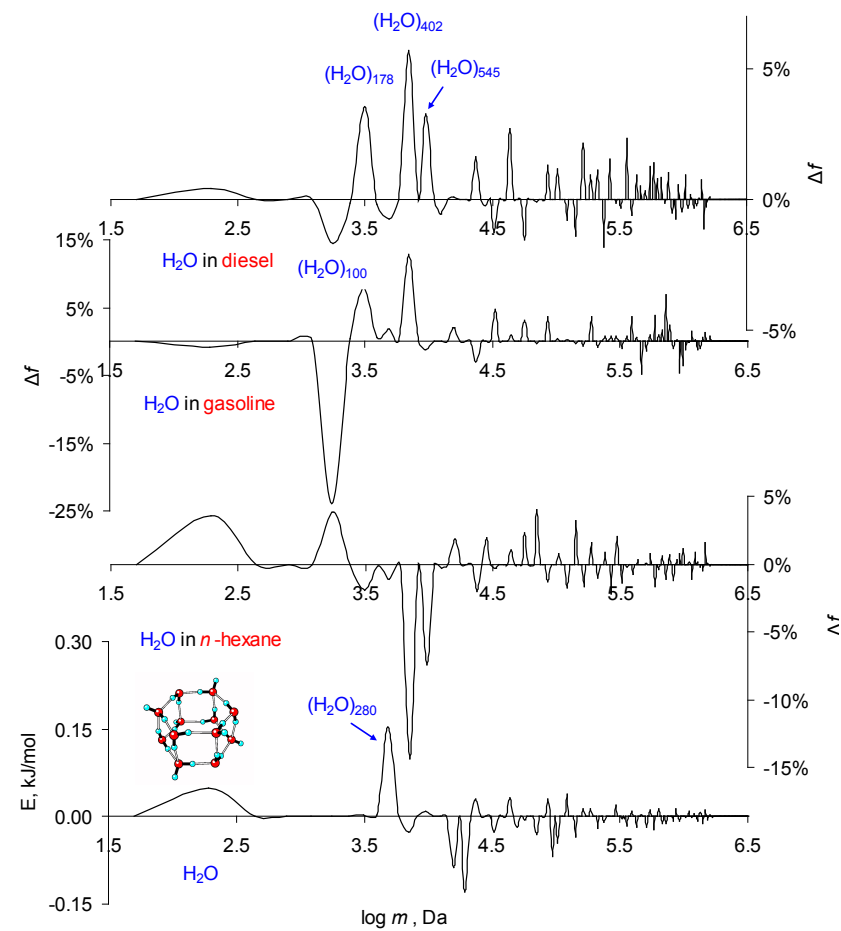

Figure 4. GMS subtraction spectra for water in hydrocarbons (explanation in text). Mass ensembles up to 3 million Daltons, $p>1 \mathrm{~N} / \mathrm{m}^{2}$

In bulk water, the signals of the clusters $\left(\mathrm{H}_{2} \mathrm{O}\right)_{100}$ and $\left(\mathrm{H}_{2} \mathrm{O}\right)_{178}$ are not available because of an equilibrium between the collapsed and expanded forms. As a result, the signals cancel each other (Figure 1). Consequently, for water clusters, the balance between the collapsed and expanded forms shall be actively influenced by hydrocarbons however, the hydrocarbon LRO itself is altered too. The signal of the Chaplin water cluster consisting of 280 molecules in hydrocarbons is expressed very poorly, while its expanded form in pure water is characterized by a very strong one. The hydrocarbon could affect the balance of expanded-collapsed so that the share of collapsed clusters approaches to that of the expanded ones leading to signal weakening. It is particularly striking that the signal intensities of the large clusters $\left(\mathrm{H}_{2} \mathrm{O}\right)_{402}$ and $\left(\mathrm{H}_{2} \mathrm{O}\right)_{545}$ have changed substantially. While they are described by weak signals in bulk water they show very strong ones in hydrocarbons, especially in $n$-hexane and diesel. These clusters are present as expanded in diesel but as collapsed in $n$-hexane, in approximately equal parts. In gasoline, the cluster $\left(\mathrm{H}_{2} \mathrm{O}\right)_{545}$ shows a very weak signal, probably due to the equilibrium of different density forms. Table 1 summarizes the main parameters of the cluster formation of investigated liquids.

Table 1. Main characteristics of the long-range order in the analyzed liquids. Where: $\mathrm{D}_{\mathrm{c}}$ - part of collapsed clusters $\mathrm{D}_{\mathrm{c}}=(\Sigma|-f| / \Sigma \mid f), \mathrm{M}_{\mathrm{GMS}}-\mathrm{av}-$ erage cluster mass $\mathrm{M}_{\mathrm{GMS}}=\Sigma|f| \cdot m, \mathrm{~N}$ - number of cluster kinds, $\mathrm{F}_{95 \%}$ - number of cluster kinds with a signal intensity reproducibility of at least $95 \%$ (skeletal clusters)

\begin{tabular}{c|c|c|c|c|c} 
Liquids & $\mathbf{M}_{\mathbf{G M S}}, \mathbf{D a}$ & $\mathbf{D}_{\mathbf{c}}$ & $\boldsymbol{N}$ & $\mathbf{F}_{\mathbf{9 5} \%}$ & $\boldsymbol{f}, \mathbf{2 6} \pm \mathbf{3} \mathbf{~ k D a}$ \\
\hline Diesel & 190241 & $69 \%$ & 52 & $67 \%$ & $-10.3 \%$ \\
Gasoline & 465554 & $66 \%$ & 49 & $75 \%$ & $-4.7 \%$ \\
$n$-Hexane & 176792 & $59 \%$ & 52 & $62 \%$ & $-6 \%$ \\
Gasoline- $\mathrm{H}_{2} \mathrm{O}$ & 168254 & $57 \%$ & 51 & $55 \%$ & $-8 \%$ \\
Diesel- $\mathrm{H}_{2} \mathrm{O}$ & 167966 & $58 \%$ & 50 & $73 \%$ & $-9 \%$ \\
$n$-Hexane $-\mathrm{H}_{2} \mathrm{O}$ & 236972 & $64 \%$ & 51 & $60 \%$ & $-8 \%$ \\
\hline
\end{tabular}

As shown in the Table 1, the addition of water to gasoline and diesel leads to a decreased average cluster mass, to reduced parts of collapsed clusters (nuclei of crystals) and numbers of cluster kinds in diesel and for gasoline only, the part of skeletal clusters has become less. Attention is drawn to the very high $\mathrm{M}_{\mathrm{GMS}}$ value in gasoline indicating the presence of large clusters. To proof this, the integral characteristics of the cluster fraction distribution are necessary to be investigated.

The integral curves of the cluster fractions $\left(\mathrm{W}_{\mathrm{x}}\right)$ in gasoline, $n$-hexane, and gasoline with water and $n$-hexane with water are described by the following relationships, respectively:

$$
\begin{gathered}
\mathrm{W}_{\mathrm{x}}=-0.0035\left(m \cdot 10^{-5}\right)^{2}+0.108\left(m \cdot 10^{-5}\right)+0.1417 \\
\mathrm{~W}_{\mathrm{x}}=0.1106 \cdot \ln \left(m \cdot 10^{-5}\right)+0.6945 \\
\mathrm{~W}_{\mathrm{x}}=0.1122 \cdot \ln \left(m \cdot 10^{-5}\right)+0.6968 \\
\mathrm{~W}_{\mathrm{x}}=0.1162 \cdot \ln \left(m \cdot 10^{-5}\right)+0.6406 .
\end{gathered}
$$

According to the first equation there are large fractions of big clusters in gasoline, whose formation might be due to its long storage (2006) in the absence of mechanical and thermal influences being responsible for the long-range order destruction. The increased $\mathrm{M}_{\mathrm{GMS}}$ could be explained by the long storing, too. The situation with long storing is known from the year 2006, when the gasoline demand in Germany fell and the storages were overcrowded and the demand for diesel fuel has risen sharply.

The introduction of water into gasoline reduces $\mathrm{M}_{\mathrm{GMS}}$ more than two times, while it is the same for gasoline and diesel fuel saturated with water. Hence water can be used to change the long-range order in hydrocarbons. Car enthusiasts have been known for some time that the addition of water to liquid fuel affects the engine performance.

Returning to Figure 4, the water cluster of 100 molecules in $n$-hexane and gasoline is characterized by different density, which implies it has other surroundings. It can be assumed that in gasoline the surface of the water cluster is formed by water molecules so that the hydrogen atoms are directed inside the cluster and on the surface are oxygen atoms mainly. In $n$-hexane, the surface water molecules are oriented differently; the oxygen atoms are directed towards the center, however, the hydrogen atoms to the surface where they interact with the hydrogen atoms of the $n$-hexane clusters by 
weak van der Waals forces. Here is this water cluster partially loosened. In gasoline, the surface oxygens of the water cluster interact with their surroundings too, but the interaction is because of the water polarity greatly weakened leading finally to a cluster individualization. Possible "partners" of such an interaction may be impurities of alcohols, ketones. In diesel, the number of possible partners is much higher and the water cluster loses its individuality, hence its signal is close to zero.

It has to be mentioned that already earlier the lamellar reorientation of atoms on the surface of water clusters has been observed by Ishiteru[19].

The important role of water clusters in hydrocarbon nanoemulsions becomes clear considering the scheme how oxygen interacts with the fuel at the level of: (i) oxidant diffusion into the reductant cluster (fuel), (ii) chemical reaction itself and (iii) products' removing (combustion gases, scheme).
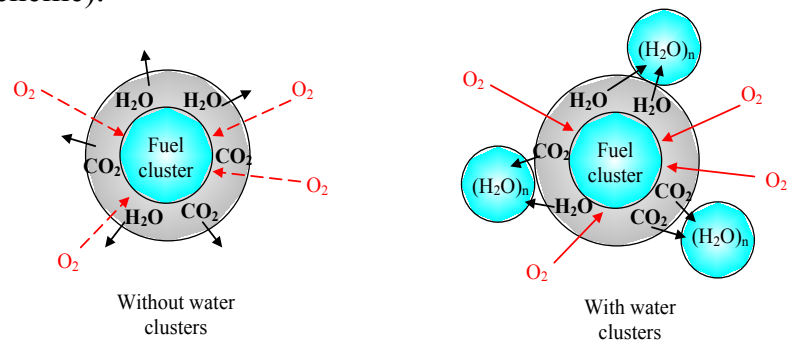

According to this scheme, the stream of reaction products prevent the penetration of oxygen into the fuel cluster however, the addition of water provides the possibility for the fast removal of the reaction products. In the following the combustion process will be accelerated, which leads to an increased fuel efficiency and higher engine power.

In conclusion, we consider the behavior of the unique cluster with the mass of $26 \pm 3 \mathrm{kDa}$ analyzed in both liquids and polymeric materials[25]. In the present study, this cluster is observed to be present in water, hydrocarbons and their mixtures thereof. Both for the mixtures of water with hydrocarbons and water itself (GMS subtraction spectra for water in hydrocarbons according to the procedure given for the Figure 4), the interaction of this cluster with the surroundings remained almost constant at $-8 \% \ldots-9 \%$ (see also Table 1). The cluster of $26 \mathrm{kDa}$ is also present in mixtures of hydrocarbons but its oscillation and interaction with the surroundings depend on the kind of fuel mixture. Table 2 presents the results obtained for this cluster.

Table 2. The cluster with the mass of $26 \mathrm{kDa}$ in different fuel mixtures (vol. \%) and its interaction with the surroundings ( $f$ at $2 \mathrm{kHz}, 286 \mathrm{~K}$ )

\begin{tabular}{c|c}
\hline Fuel kinds & $\boldsymbol{f}$ \\
\hline gasoline, $\mathbf{1 0 0} \%$ & $\mathbf{- 4 . 7} \%$ \\
\hline $99 \%$ & $-3 \%$ \\
\hline $95 \%$ & $-5 \%$ \\
\hline $90 \%$ & $-7 \%$ \\
\hline $80 \%$ & $-9 \%$ \\
\hline $70 \%$ & $-11 \%$ \\
\hline diesel, $\mathbf{1 0 0} \%$ & $\mathbf{- 1 0} \%$
\end{tabular}

As shown in Table 2, this cluster oscillates in all mixtures as a collapsed oscillator $(-f)$. If the proportion of diesel increases in gasoline, then also raises the individuality of this unique cluster (decreased interaction with surroundings). Based on the decreasing of the $f$ value, the presence of two cluster kinds in fuel mixtures can be assumed: gasoline and diesel clusters, which are immiscible. These are to be understood as an accumulation of similar clusters ("clouds") in a neighborhood of other clusters. In the saturated state, these mixtures of liquids can be imagined as systems consisting of these clouds, which is recognized by the different $f$ values for the mixtures of $95 \%, 70 \%$ and for diesel. When water in the fuel or $n$-hexane is present, these hydrocarbon clusters seem to disappear and to be replaced by a water cluster (stability of $f$ amounts to $-8 \%$ ).

It has to be mentioned that all cluster sequences in hy-drocarbons, water[8], polymers[25,26], solutions[27], pro-tein coils (lysozyme, L-arginine, Chymotrypsinogen-A[12]) and polysaccharides ([28] amylopectin, etc.) are character-ized by similar masses. Common is the cluster sequence consisting of the masses given in Table 3 (only the first 9 sequence members).

Table 3. Mass concentrations and their oscillation frequencies analyzed in liquids, polymers and biomolecules (explanation in text)

\begin{tabular}{c|c|c}
$\mathbf{N}$ & $\boldsymbol{m}, \mathbf{k D a}$ & $\boldsymbol{\omega}, \mathbf{k H z}$ \\
\hline 1 & $0.2 \pm 0.02$ & 22.2 \\
2 & $1.8 \pm 0.1$ & 7.4 \\
3 & $3.1 \pm 0.1$ & 5.5 \\
4 & $4.9 \pm 0.5$ & 4.4 \\
5 & $7.0 \pm 0.5$ & 3.7 \\
6 & $9.5 \pm 0.5$ & 3.2 \\
7 & $12.5 \pm 0.5$ & 2.8 \\
8 & $15.7 \pm 0.5$ & 2.5 \\
9 & $26 \pm 3$ & 2.0
\end{tabular}

The sequence is well described by the following relationship:

$$
m=268.19 \cdot \mathrm{N}^{2.06}
$$

\section{Conclusions}

At the level of molecular mass concentrations - clusters, liquid fuels are characterized by a long-range order they are designated as nano-colloidal systems, therefore.

In fuel mixtures proceeds a distribution of molecules according to their nature and new cluster ensembles will be formed, which are stabilized by gravitational white noises.

The role of water in the formation of long-range order in liquid fuels is that it favors the formation of a thermodynamically stable nanoemulsion.

The hierarchy in the formation of nanoemulsions represented by molecules' clusters of the same nature is a sequence of oscillating masses (clusters and their associates at submicellar and micellar level).

The results obtained can be applied for a rapid and non-destructive monitoring of liquid fuels and other petroleum products. 


\section{REFERENCES}

[1] Shinichi Hirabayashi, Koichi MT Yamada. The monocyclic water hexamer detected in neon matrices by infrared spectroscop. Chem. Phys. Letters 2007;435; 74-8.

[2] Urano Noritsugu. Functional water for improvement of hydrocarbon based liquid fuel JP 2001064662 A2 20010313. Application No. JP 1999-241435 1999 0827, IPC: C10L001-12 Jpn. Kokai Tokkyo Koho (2001), 5.

[3] Uzawa Masakazu. Method for treating for hydrocarbon fuel JP 2002256273 A2 20020911, Applic. No. JP 2001-59782 20010305. Jpn. Kokai Tokkyo Koho (2002), 11 pp. IPC: C10G032-00.

[4] McVitty Aaron. Improvement relating to fuel conditioning PCT Int. Appl. (2004) 19pp. WO 2004044101 A2 20040527. Appl. WO 2003- GB4955 20031114.

[5] Johnson Keith H, Zhang Bin. Stabilized water nanocluster-fuel emulsion designed through quantum chemistry PCT Int. Appl. (1998), 91 pp. WO 9821294 A1 19980522. Appl.: WO 97- US20779 1997114. IPC: C10L001-32.

[6] Fu da-you, Yuan Dong, Tan Wen-yuan, Xiang Shuang-guan. Cluster analysis method for gasoline.Jilin Huagong Xueyuan Xuebao 2005;22;6-10.

[7] Mudzhikova GV, Brodskaya EN. Molecular dynamics simulation of small water clusters in nonpolar n-hexane. Vestnik Sankt Petersbugskogo universiteta, seria 4. Fisika, Chimija 2004;4;71-7, in Russian

[8] Zubow KV, Zubow AV, Zubow VA. Cluster structure of liquid alcohols, water and n-Hexane. J. of Appl. Spectr $2005 ; 72 ; 321-28$.

[9] Zakharov VV, Brodskaya EN, Laaksonen A. Molecular dynamics simulation of methanol clusters. J. Chem. Phys 1998;109; 9487-9493.

[10] Shruti Maheshwary, Nitin Patel, Narayanasami Sathyamurthy. Structure and Stability of Water Clusters $\left(\mathrm{H}_{2} \mathrm{O}\right) \mathrm{n}, \mathrm{n}=8$ $\mathrm{An} \mathrm{Ab}$ Initio Investigation. J. Phys. Chem. A 2001;105; 10525-37.

[11] Fesenko E.E., Terpugov E.A. About unusual spectral properties of water in a thin layer. Biofisika 1999;44;5-9, in Russian.

[12] Zubow KV, Zubow AV, Zubow VA. Principles of gravitation spectroscopy. New form of molecular matter. Processes. Fields. Aist Handels- und consulting gmbH, dep. R\&D, Berlin, electronic book (www.zubow.de),; 2010. (in Russian).

[13] Zubow KV, Zubow AV, Zubow VA. Ensemble of Clusters New Form of Molecular Matter, Risks and Chances. Zubow Equations. In: Taylor JC, editor. Advances in Chemistry Research, New York: Novapublisher; 2010, vol. 5, p. 107-45.

[14] Pagliai M., Cardini G., Righini R., Schettino V. Hydrogen bond dynamics in liquid methanol. J. Chem. Phys. 2003;119; 6655-63.
[15] Tomas Rocha-Rinza, Luca De Vico, Valera Veryazov, Björn O. Roos. A theoretical study of singlet low-energy excited states of the benzene dimer. Chem. Phys. Letters 2006; 426;268-72.

[16] Herbert C. Georg, Kaline Continho, Sylvio Canuto. Converged electronic polarization of acetone in liquid water and the role in the $n-\pi^{*}$ transition. Chem. Phys. Letters 2006;429; 119-23.

[17] Erin R. Johnson, Gino A. DiLabio. Structure and binding energies in van der Waals dimers Comparison between density functional theory and correlated ab initio methods. Chem. Phys. Letters 2006;419; 333-39

[18] Lenz A, Ojamäe L. On the stability of dence versus cage-shaped water clusters: Quantum- chemical investigations of zero-point energies, free energies, basis-set effects and IR spectra of $\left(\mathrm{H}_{2} \mathrm{O}\right)_{12}$ and $\left(\mathrm{H}_{2} \mathrm{O}\right)_{20}$. Chem. Phys. Letters 2006;418;361-67.

[19] Yoshiteru Yonetani. A severe artifact in simulation of liquid water using a long cut-off length: Appearance of a strange layer structureChem. Phys. Letters 2005;406;49 - 53.

[20] Giuseppe Graziano. Benzene solubility in water: A reassessment. Chem.Phys. Letters 2006;429;114 -18.

[21] Upadhyay D.M., Mishra P.C. Binding of benzene with water clusters $\left(\mathrm{H}_{2} \mathrm{O}\right) \mathrm{n}, \mathrm{n}=1-6$, in the ground and lowest singlet excited states. THEOCHEM 2002;584;113 - 33 .

[22] Keith M. Murdoch, Thomas D. Ferris, John C. Wright, Thomas C. Farrar. Infrared spectroscopy of ethanol clusters in ethanol-hexane binary solutions. J of Chem. Phys 2002; 116; 5717-25.

[23] Dolgopolova AV, Kushnarev DF, Qua KIm En, Kalabin GA, Schmidt FK. Proton and oxigen- 17 NMR spectroscopic study of hidrophilic-hydrophobic interactions in aqueaus solutions of petrolium products. Khimiya I technologiya vody 1993;15;107-12, in Russian.

2Q44] Bogdanov EV, Manturova GM. Equiclaster model of water. Biomedicinskaja Radioelektronika 2000;7;19-28, in Russian.

[25] Zysman V, Nguyen Tuan Q, Kausch, Henning H. Degradation on freezing dilute polystyrene solutions in $p$-xylene $/ \mathrm{J}$ Polym. Sci., Part B: Polym. Phys 1994;32;1257-69.

[26] Zubow KV, Zubow AV, Zubow VA. Study of structural changes in a LDPE film by flicker- noise spectroscopy. Plasticheskie Massy 2006;3;32-4, in Russian.

[27] Zubow KV, Zubow AV, Zubow VA. Spectra of seed cristalls oscillation of $\mathrm{NaCl}$ in water solution. J. Appl. Spectr 2005;72; 766-72.

[28] Zubova KV, Zubov AV, Zubov VA. Low frequency movement of cluster-12 in potato amylopectin during growth. Influence of white noises. Khimiya Rastitel'nogo Syr'ya 2009;2; $77-87$ 